for processing Irish moss. Work is being continued to find a commercial method for preparing a good gelling substance from this seaweed. Work has been undertaken on improvement of the stability and other properties of lard as a suitable alternative for other vegetable oil shortenings. A survey was made of the vitamin intake of Canadian Army troops garrisoned at district depots, and much work has been done on the development of substitutes for metal containe tith special reference to the packaging of dehydrated foods for export or Army use. The Fermentation Section's staff has been increased from four to fourteen members, and much of the time of the Section has been devoted to the study of the manufacture of butylene glycol from wheat by a fermentation process. Pilot plant is under construction.

In the Division of Chemistry, research on photo. sensitized reactions has continued, but experimental alkaloid research has been on a reduced scale. Fundamental investigations on the chemistry of leather and plastics have continued, and that Section has been considerably enlarged to take care of the test work required by the Armed Services and Inspection Board. The laboratories of the Textile Section were occupied chiefly with defence work involving investigations on substitute materials and preparation of purchase specifications, acceptance tests and fundamental research on problems arising out of war uses of textiles. The Paint Laboratory has been occupied. to an increasing extent with the needs of the Services for special paints, lacquers, protective coatings, shellfilling material, anti-freezes, etc. The Rubber Laboratory has given special attention to the study of rubber substitutes and synthetic rubber.

In the Division of Mechanical Engineering, all work having no bearing on the war effort has been suspended or abandoned. Installation of the driving and controlling equipment of the horizontal wind tunnel has been completed, and calibration and adjustment of the vertical spinning tunnel are proceeding. The staff of the Division of Physics and Electrical Engineering has been further increased, and, as before, the bulk of the investigations have been of a secret nature and not at present suitable for publication. The General Physics Section has been engaged largely on naval work, ballisties and the design of fire-control gear, as well as on the development of equipment for one phase of antisubmarine warfare. Work in the Optics Section has involved research and development in optical instruments, photography, spectrochemical analysis and geometrical optics as well as the making of a large number of optical components of military instruments in the optical shop.

The Section on Codes and Specifications has been restricted during the War to a maintenance basis in respect of its two main branches-the National Building Code and the Canadian Government Purchasing Standards Committee. The Research Plans and Publications Section, which is responsible for the conduct of the National Research Council Library, refers to the increasing use of the Library, to its bibliographic work and literature searches, technical inquiry work and the issue of the Canadian Journal of Research.

Other details of the war work of the Divisions are included in the president's report, which also gives a survey of extra-mural activities of the Council. Among these may be specially mentioned the Service committees established under the Associate Com- mittee on Medical Research to deal with Aviation Medical Research, Naval Medical Research and Army Medical Research. The first has carried out an impressive programme of work in the fields of highaltitude flying, protective clothing for flyers, oxygen equipment and in special studies relating to personnel selection. The second, in addition to dietary surveys in vessels under operating conditions and in shore establishments, has carried out experiments on the use of vitamin $\mathbf{A}$ to improve night vision. Special lighting techniques designed to minimize interference with night vision have been devised for use on bridge controls, bridge instruments and chart tables. Special tests elaborated for the evaluation of night vision, colour vision, and visual acuity have been adopted. by the Navy, while experimental work on fatigue of personnel operating anti-submarine detection devices has yielded information which has been applied in determining the watch period to be used for this work. Other investigations have covered underwater blast injury, eye-protection for bridge and look-out personnel, obtaining fresh water from seawater in lifeboats, protection of naval personnel from noise, combating fatigue in radio detector and wireless operators, and sea-sickness problems. Another war-time committee of the Council has co-ordinated and directed research in Canadian universities on sixty projects concerned with the production of explosives now in use and the development of new explosives.

\section{THIRD ANNUAL MEETING OF THE ANTI-FASCIST SOCIETY OF SOVIET SCIENTISTS \\ By VICTOR KRASILNIKOV*}

DROMINENT representatives of Soviet science Pattended the third meeting of the Anti-fascist Society of Soviet Scientists held in Moscow on June 18. In his opening remarks, the president, Derzhavin, reminded his audience of the solemn oath taken by them at their first meeting in the memorable days of October 1941 when the German Army was driving on to the capital of the U.S.S.R. They then vowed to devote all their energy and knowledge to the war effort of the nation. Soviet men of science, he said, have kept that vow.

An eloquent speech was made by the vice-president of the Academy of Sciences, Alexander Baikov. $\mathrm{He}_{\mathrm{e}}$ gave an account of the great contributions of Soviet men of science to the war effort. Metallurgists have speeded up existing processes of production, and introduced important improvements in the technology of iron and steel production. Geologists have discovered new deposits of manganese, mercury, lead and petroleum. Botanists have investigated new varieties of medicinal herbs and vitamin-yielding plants. Agricultural scientists have helped to increase crop-yields. Medical scientists have shown numerous examples of self-sacrificing service to their country.

Prof. Peter Kapitza, of the Academy of Sciences, remarked that since the second meeting of the Society, in July 1943, many stirring and cheering events have taken place. But, while rejoicing at the Army's advance, in the course of which Russian territory is being liberated from the hands of the

\footnotetext{
* Transcribed and prepared by $\Lambda$. Clifford.
} 
invader, scientific workers cannot but be deeply pained by the damage which the enemy is inflicting on the country. "We scientists have reason to feel gratified by the fact that we have been able to help, with our knowledge, to improve the armaments of the army, and to facilitate the struggle against German barbarity."

The audience listened with great interest to the speech delivered by Prof. Maria Petrova, of Leningrad. She remained in Leningrad all through the siege. "It was painful," she said, "to see how German artillery destroyed the scientific and public institutions of the city, but I never for one moment lost faith that the enemy would be defeated. Work was the best answer to the crimes of the barbarians. During the siege I completed twelve scientific investigations."

Igor Grabar told of the appalling destruction by the Germans of monuments of Russian art in Novgorod and in the environs of Leningrad. Prof. P. V. Pavlov, of the University of Odessa, who lived in that city during its occupation by Germans and Rumanians, and Prof. Alyoshin, of the University of Kiev, who likewise saw all the horrors of German occupation, spoke of the damage done by the invaders to scientific and cultural institutions in the Ukraine. This was also the subject of a speech by Alexander Beletsky, of the Ukrainian Academy of Sciences.

Nikolai Nikolsky, member of the White Russian Academy, told the meeting of the 'new order' in German-occupied Minsk. This elderly grey-bearded scholar escaped from Minsk with the aid of White Russian partisans in August 1943. He had spent seven months with a partisan detachment, and only in April 1944 made his way to the "mainland", as partisans call Soviet territory across the front line. Prof. Krisciunas spoke of the plight of the intelligentsia in German-occupied Lithuania. Nikolai Propper-Grashchenkov, corresponding member of the Academy of Sciences, denounced the practices of German physicians. He said that the Soviet medical profession is in possession of irrefutable proofs of the participation of representatives of German science in the killing of prisoners-of-war and of mentally diseased people, and in the bleeding of Soviet children for blood transfusions to such an extent that the children died. They also have documents showing that German surgeons carried out experimental operations on prisoners-of-war.

Alexander Poraj-Koszyc, another member of the Academy, made an inspiring speech in which he called upon the scientifis and professional men of Poland to devote all their efforts to the defeat of Hitlerism.

Many messages of greeting were received from various institutions as well as from private individuals in the Soviet Union and abroad. The meeting enthusiastically adopted the text of a message of greeting to the Commander-in-Chief of the Armed Forces of the U.S.S.R., Joseph Stalin, and issued an appeal to men of science throughout the world. This appeal said, among other things: "Fascism is the most malignant foe of science and culture. ... There is only one way to save human beings and cultural treasures, and that is, to defeat Germany and her satellites at the earliest possible date. ... All of us must take an active part in this struggle. Let every intellectual and every scientific worker who is not fighting 'arms in hand' contribute his mite to the common cause of humanity by intense creative effort."

\section{EARTHQUAKES IN SOUTHERN CALIFORNIA}

RENO GUTENBERG and C. F. Richter have re. cently studied in detail several hundred earth. quakes in southern California with the view of finding out the physical properties of the earth's crust in the region. The first paper under discussion, "Recent Results of Earthquake Study in Southern California", by both authors (Trans. Amer. Geophys. Union, 1943) contains first the travel-time equations of the district. These are :

$$
\begin{array}{ll}
\bar{P}-0=D / 5 \cdot 577 & \bar{S}-0=-0 \cdot 5+(D / 3 \cdot 26) \\
P y=0=1 \cdot 2+(\Delta / 6 \cdot 05) & S y=0=2 \cdot 0+(\Delta / 3 \cdot 64) \\
P n-0=6+(\Delta / 8 \cdot 06) & S n-0=8+(\Delta / 4 \cdot 46)
\end{array}
$$

where $\Delta$ is epicentral distance in $\mathrm{km}$. and $D$ is hypocentral distance for focal depth of $18 \mathrm{~km}$.

The authors state that the terms independent of $\Delta$ in the equations for $P n$ and $S n$ show appreciable variation for shocks in different parts of the region, with maxima of about 9 and 13 respectively in the shocks of northern Owens Valley east of the Sierra Nevadà. This is an effect of the 'root' of the Sierra.

The travel-times indicate no variation in the thickness of the 'granitic' layer, which is about $18 \mathrm{~km}$. Most of the shocks originate near the base of this layer. There is at least one 'intermediate' layer between this and the base of the continental crust (the Mohorovicic discontinuity). The velocity of $P y$ in this layer differs notably from that of the similar wave $P^{*}$ as observed in Europe $(6.05$ instead of $6.4 \mathrm{~km}$. $/ \mathrm{sec}$.). If this is a single layer, its thickness varies from about $20 \mathrm{~km}$. in the coastal area to almost $50 \mathrm{~km}$. in the Sierra region.

The term -0.5 in the equation for $\bar{S}$ represents a frequently noticed discrepancy between the apparent origin-times of $\bar{P}$ and $\bar{S}$. The writers attribute this to development of the fault-fracture with speed greater than the velocity of transverse waves, resulting on the average in early arrival of $\bar{S}$ at the observ-

\begin{tabular}{|c|c|c|c|}
\hline Layer & $\underset{\text { Modulus }}{\text { Bulk- }}$ & Rigidity & $\begin{array}{l}\text { Poisson's } \\
\text { Ratio }\end{array}$ \\
\hline $\begin{array}{l}\text { Granitic } \\
\text { Intermediate } \\
\text { Below Intermediate }\end{array}$ & $\begin{array}{r}4.5 \times 10^{11} \\
5.5 \times 10^{11} \\
12.4 \times 10^{11}\end{array}$ & $\begin{array}{l}2.9 \times 10^{11} \\
3.8 \times 10^{11} \\
6.5 \times 10^{11}\end{array}$ & $\begin{array}{l}0 \cdot 24 \\
0.22 \\
0 \cdot 28\end{array}$ \\
\hline
\end{tabular}
ing stations. The following are mean values of elastic constants (c.G.s. units) from all available data for the region:

J. M. Nordquist is in the course of developing a new application of the magnitude scale in association with these earthquakes. Assuming a special distribution function already employed by E. J. Gumbel in the investigation of flood-statistics ("Statistical Control-Curves for Flood-Discharges." By E. J. Gumbel, Trans. Amer. Geophys. Union, 489-509; 1942) makes it possible to choose a scale for a plot in which the points for various magnitudes fall nearly on a straight line, the level of which is an indication of the degree of activity. This method promises a quantitative definition of seismicity.

The second paper here discussed is "Variations in Physical Properties within the Earth's Crustal Layers", by Beno Gutenberg (Trans. Amer. Geophys. Union, 1943). In it the author states that the traveltimes as well as the amplitudes lead independently to the conclusion that most of the fifty shocks discussed in this second paper originated at the bottom. 